monio, con doña Isabel de Aragón, cuya celebración sitúa la autora «en una fecha temprana pero imprecisa en torno a $1685{ }^{\prime 2}$. En el curso de nuestras investigaciones en los diversos archivos de las parroquias madrileñas, tropezamos hace tiempo con el registro de este primer matrimonio, que se celebró concretamente el día 4 de agosto de 1681 en la iglesia parroquial de los Santos Justo y Pastor ${ }^{3}$, cuando Ardemans contaba tan sólo veinte años de edad. Literalmente, la partida de su matrimonio dice así:

(Al margen: Theodoro Ardemanes con Isabel de Aragón).

En la Villa de Madrid, a quatro días del mes de Agosto año de mil seiscientos y ochenta y uno, Yo, Joseph de Manzanares, Cura theniente desta Yglesia Parrochial de S. Justo y Pastor de dicha Villa, en virtud de Mandamiento de el Sr. Dr. D. Antonio Pascual, Vicario de ella y su Partido, despachado en dos deste dicho mes y año Por Juan Baptista Sáez Bravo, notario, Y no habiendo precedido ninguna de las tres amonestaciones que dispone y Manda el santo concilio de trento por haber dispensado dicho señor Vicario en todas ellas, Por justas causas que a ello le mobieron, y después de haberles tomado su mutuo consentimiento, desposé Por palabras de presente, que hacen Berdadero y Legítimo Matrimonio, a Theodoro Ardemanes con Isabel de Aragón, mis Parrochianos, estando en la calle de los embajadores, casas de Manuel del Olmo, siendo thestigos Christóbal Tello, Ysidro Rusexas y Andrés Pérez, y lo firmé. Joseph de Manzanares (firmado y rubricado).

Una anotación al margen se refiere a las «Vendiciones de primeras Nupcias», que recibieron igualmente en la parroquia de los Santos Justo y Pastor el 6 de febrero de 1682.

Parece más que probable que el propietario de las casas de la calle de Embajadores en las que habitaba Ardemans fuera el también conocido arquitecto Manuel del Olmo, y que el testigo Cristóbal Tello fuese el maestro de obras de igual nombre de que se hace mención en diversos documentos de la época ${ }^{4}$.

Natividad Galindo San Miguel Museo del Prado

\title{
SANTA CATALINA DE SIENA Y LA GÉNESIS DEL RETRATO DE LA BEATA MADRILEÑA MARÍA ANA DE JESÚS (1564-1624)
}

El 25 de mayo del año 1783, en un solemne acto celebrado en la Basílica Vaticana, es beatificada por Pio VI la religiosa mercedaria María Ana de Jesús ${ }^{\text {. }}$

La beata madrileña, había nacido en el año 1564 en el seno de una familia noble, su padre

2 Ob. cit., p. 75.

3 Madrid, archivo parroquial de San Justo y Pastor, fol. 449 del Libro De Despossorios y Belaciones de esta Iglessia Parrochial de Sant Iusto y Pastor de Madrid. Empieza desde IX. de Henero de M.DC.LXX.II.

${ }_{4}$ Virginia Tovar Martín: Arquitectos madrileños de la segunda mitad del siglo XVII, Madrid, Instituto de Estudios Madrileños, 1975, Manuel del Olmo, pp. 209-228; Cristóbal Tello, p. 221.

1 Bibliotheca Sanctorum, Roma (1967), vol. VIII, pp. 1032-1033. El decreto firmado por el Santo Padre, está fechado el 18 de Enero de 1783. En un breve del 13 de mayo del mismo año, se aprobaban los dos milagros atribuidos a la santa, produciéndose la solemne proclamación pública, doce días más tarde. 
Luis Navarro de Guevara, servía en la Casa Real y acompañando a ésta, había residido sucesivamente en Madrid y Valladolid.

Tras una vida plagada de sacrificios y mortificaciones, la virtuosa religiosa fallecerá en su villa natal el 11 de Abril de $1624^{2}$.

La venerada Madre Mercedaria, había conocido en el último periodo de su vida un gran reconocimiento público, como lo demuestran las frecuentes visitas de gente de toda condición, atraidas por su fama de santidad. Es este un fenómeno muy frecuente en la España Barroca, siendo numerosos los casos de personas famosas por su virtud ascética, a los que se le atribuían cualidades milagrosas aun en vida ${ }^{3}$.

El reconocimiento popular del que gozó en los postreros años de su existencia la religiosa de origen navarro, explicaría la extraordinaria difusión de la devoción a su imagen tras su muerte, incluso antes de su beatificación ${ }^{4}$.

$\mathrm{Al}$ respecto, podemos señalar el interés de Vicente Carducho por el retrato de la mercedaria, a la que efigiaría al menos en tres ocasiones, siendo el más temprano el óleo existente en la catedral de Almeria fechado en el año $1625^{5}$.

No podemos olvidar que el pintor y tratadista florentino, asiduo de la Corte, había obtenido la mascarilla funeraria de la piadosa madrileña, convirtiéndose por lo tanto, en el más cualificado transmisor de la «verdadera imagen» de Sor María Ana de Jesús ${ }^{6}$.

El excepcional eco que alcanzó la ascética vida de la monja madrileña, se manifestó a nivel oficial en la colocación de su efigie, junto a la de otros santos de la Orden de la Merced, en la antigua Puerta de Alcalá (Fig. 14) ${ }^{7}$.

En este contexto deberíamos recordar, que el culto público por iniciativa popular hacia personas de reconocida virtud, contravenía las disposiciones tridentinas, las cuales jamás supusieron un freno absoluto para su desarrollo en la España Barroca ${ }^{8}$.

Tras la beatificación de Sor María Ana de Jesús, acaecida en el año 1783, se reavivará una

2 La Leyenda de Oro, Barcelona (1896), vol. II, pp. 81 y ss.

$3 \mathrm{Al}$ respecto podemos señalar el muy conocido caso, del beato Alonso de Orozco, "médico a lo divino" cuyos servicios fueron solicitados por la Casa Real. Vid. Javier Varela: La muerte del rey. El ceremonial funerario de la monarquía española (1500-1885), Madrid (1990), p. 75.

4 Fueron numerosas las relaciones sobre la ascética vida y milagros de Sor María Ana de Jesús, algunas de ellas muy tempranas, lo que alimentaría la devoción a la beata castellana. Quizás la primera redacción de los hechos, corresponde al Arzobispo de Málaga y Salerno, Gabriel de Trejo y Paniagua que había conocido a la religiosa y que impulsará el proceso en el año 1627. Algunos datos sobre la beata madrileña, se habían incluido algunos años antes de su muerte en la obra del religioso mercedario Fray Bernardo de Vargas (Chronica Ordinis B. Mariae Virginis de Mercede, Palermo, 1620). De estas tempranas relaciones sobre la vida de Sor María Ana de Jesús destaca la realizada por Fray Juan de la Presentación (La Corona de Madrid, vida de la venerable madre Mariana de Jesús, religiosa del... orden de N. S. de la Merced, Madrid, 1673). Pocos años antes de la beatificación, se publicó la obra de Fray Pedro del Salvador (La Azucena de Madrid, la venerable Sor Mariana de Jesús. Madrid, 1764), que incluía un retrato de la religiosa obra de Moncada y que se reutilizaría en la reedición de la anteriormente citada relación de Fray Juan de la Presentación, publicada de nuevo en Madrid en el año 1784 .

5 Angulo Iñiguez, Diego y Pérez Sánchez, Alfonso: Pintura madrileña en el primer tercio del siglo XVII, Madrid (1969), pp. 173 y ss.

6 Presentación, Juan de la: La Corona de Madrid. Vida de la Venerable Mariana de Jesús, Madrid (1673), pp. 313-314.

7 Un estampa anónima existente en el Museo Municipal de Madrid recuerda el evento, señalando que dicha efigie se colocó por decreto de la villa en el año 1636. La imagen de la beata María Ana de Jesús acompañaba a la de San Pedro Nolasco, fundador de la Orden de la Merced. Vid. Carrete, Juan; Vega, Jesusa, y De Diego, Estrella: Catálogo del Gabinete de Estampas del Museo Municipal de Madrid, Madrid (1985), vol. II, p. 564.

8 Como ejemplo de este fenómeno se puede señalar la muy conocida polémica de la que fue involuntariamente protagonista el padre Francisco Jerónimo Simón. Tras la muerte del piadoso valenciano, acaecida en el año 1612, y pese a la oposición de las autoridades religiosas, recibió culto por parte del pueblo valenciano, llegándose a realizar imágenes y altares dedicados al virtuoso clérigo. Vid. Kowal, Martin: Ribalta y los ribaltescos, Alzira (1985), pp. 71 y ss. 
devoción que poseía ya más de un siglo de antigüedad, plasmándose gráficamente en numerosas estampas que reproducirán su imagen durante varias décadas 9 .

Analizando la tipología de estos retratos realizados en un corto espacio de tiempo, observamos que prácticamente pueden reducirse a dos formas básicas.

En primer lugar, la que presenta a la beata madrileña coronada de espinas, sujetando en sus manos un crucifijo (en algunas ocasiones porta los clavos), tanto de medio como de cuerpo entero, encontrándose la religiosa en oración o en éxtasis.

A este tipo pertenecerían las estampas realizadas por Juan Fernando Palomino, Juan Gómez de Navía o Manuel Bru entre otros (Figs. 15, 16, 17) ${ }^{10}$.

La segunda tipología, haría referencia a las propias visiones de la religiosa, en una de las cuales contempló a la Virgen con el Niño, pudiendo la beata colocar su rosario a los pies de Jesús ${ }^{11}$.

En esta iconografía Sor María Ana de Jesús, aparece arrodillada al lado de una cruz, portando la corona de espinas y su rosario, frente a la divina aparición (Fig. 18).

En relacion con la primera iconografía, parece claro que ésta no fue creada tras su beatificación, sino que se fundamentó en otros modelos anteriores muy extendidos. Ni siquiera Carducho, cuyo retrato de la madrileña, fue grabado por Juan Fernando Palomino en el año 1785, será el creador de este modelo (Fig. 19) ${ }^{12}$.

Ya señalaba E. Panofsky, como en el siglo xv eran frecuentes los retratos de personajes con los Instrumentos de la Pasión, directamente derivados de la «Imitatio Christi» ${ }^{13}$.

Al respecto podemos recordar la estampa que grabada por Israel van Meckenem (14501503) representa a Santa Catalina de Siena. El buril norteño nos muestra a la religiosa dominica, canonizada en el año 1461, portando la corona de espinas mientras en sus manos sujeta un crucifijo (Fig. 20). De esta iconografía muy extendida, podemos señalar algunos ejemplo realizados en nuestro país en los inicios de la imprenta, como es el retrato que ilustrara la biografía de la santa editada por Juan Joffre (Valencia, 1511) (Fig. 21) ${ }^{14}$.

Es probable que el retrato de Santa Catalina de Siena, muy reproducido tanto en pintura como en el mundo del grabado en la península, sirviera como fuente de inspiración para el de nuestra beata. Es este un fenómeno frecuente en la iconografía sacra, como han demostrado algunos investigadores ${ }^{15}$.

9 Una de las primeras estampas que difundirían la iconografía de la beata es la ya comentada obra de Antonio Giovanni Faldoni, ilustración de la biografía de la beata realizada por Fray Pedro del Salvador (La Azucena de Madrid) en el año 1764. El mediocre retrato representa a la beata arrodillada frente a un altar de cuyo sagrario sale un rayo hacia la religiosa. Esta iconografía, aplicada a otros santos, no parece que tuviera continuidad en relación con Sor María Ana de Jesús, como podemos apreciar al contemplar los retratos conservados de la beata. Páez, Elena: Iconografía Hispana. Catálogo de los retratos de personajes españoles de la Biblioteca Nacional, Madrid (1966), vol. III, p. 201 n. ${ }^{\circ} 402$ (1).

10 Arte y Devoción. Estampas de imágenes y retablos de los siglos XVII y XVIII en iglesias madrileñas, Madrid (1990), pp. 36, 37, 95, 144 y 145. En el catálogo de esta exposición celebrada en Madrid en el año 1990, podemos encontrar abundantes ejemplos de lo expuesto, con escasas variantes. Las representaciones de medio cuerpo son simplemente una reducción de las de cuerpo entero, directamente inspiradas en los retratos de V. Carducho.

11 La Leyenda de Oro, ob. cit., p. 84.

12 Parece ser que Juan Fernando Palomino grabó el retrato a partir del dibujo de José del Castillo, que habría copiado uno de los lienzos de Carducho conservado en el Casón del Buen Retiro. Catálogo del Gabinete de Estampas del Museo Municipal de Madrid, ob. cit., vol. II, p. 327 n. ${ }^{\circ} 115$ (4).

13 Panofsky, E.: Vida y obra de Alberto Durero, Madrid (1982), p. 69.

14 La entalladura, de trazos muy populares, parece relacionada con la lámina de Israel van Meckenem, aunque dicha iconografía poseía ya larga tradición en la historia de la plástica. La Colegiata de Daroca conserva una tabla fechada en la segunda mitad del siglo xv que reproduce la conocida imagen de la santa italiana, portando la corona de espinas, el libro y el corazón.

15 Mâle, Emile: Barroco, Madrid (1985), p. 176. Es curioso estudiar lo ocurrido con la estigmatización de Santa Catalina de Siena, que se inspiraría en su representación gráfica en la homónima de San Francisco de Asís. Este hecho reflejaría el enfrentamiento de las dos órdenes que alcanzará su mayor fuerza durante el siglo xv. Vid. Réau, Louis: Iconographie de l'art Chrétien, París (1958), vol. II, p. 273. 


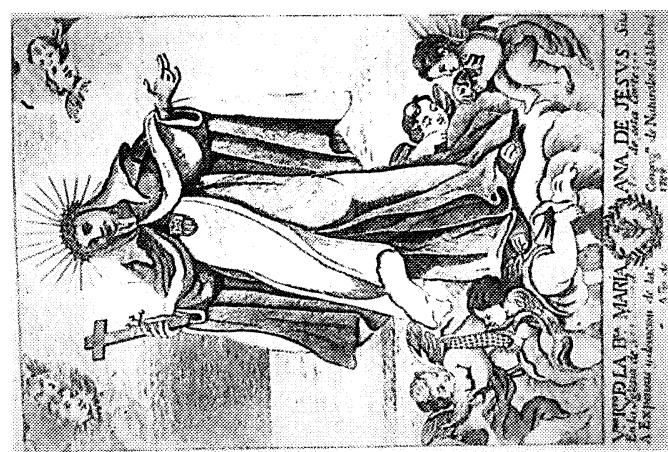

든

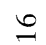

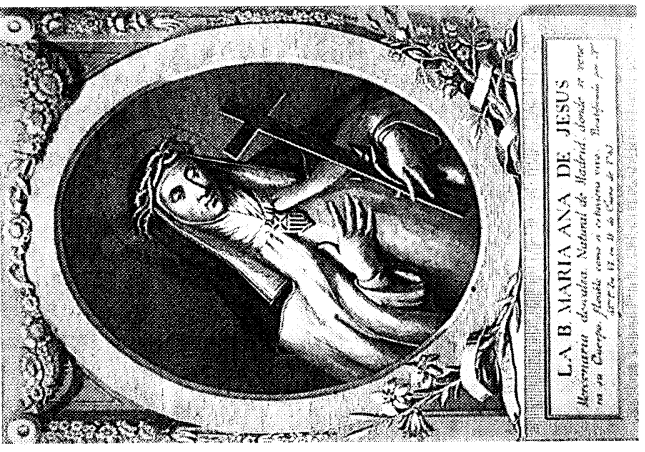

n

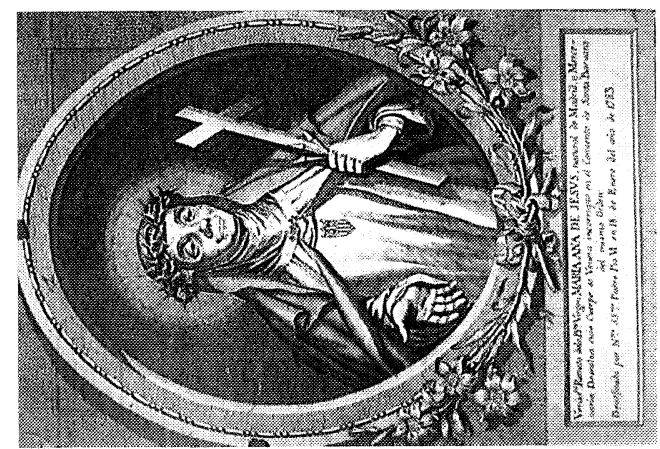

$\pm$

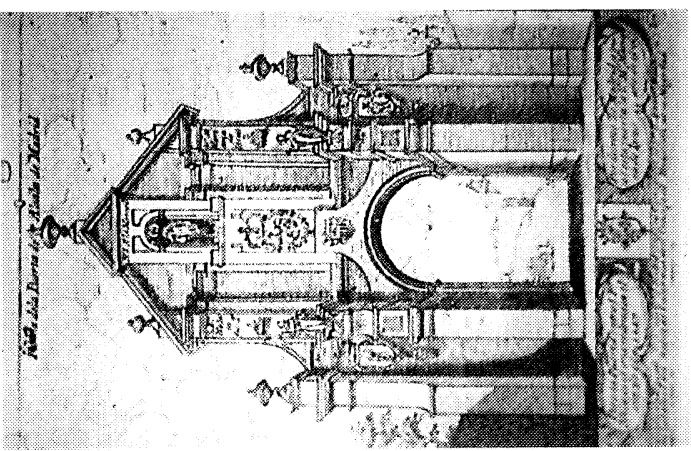

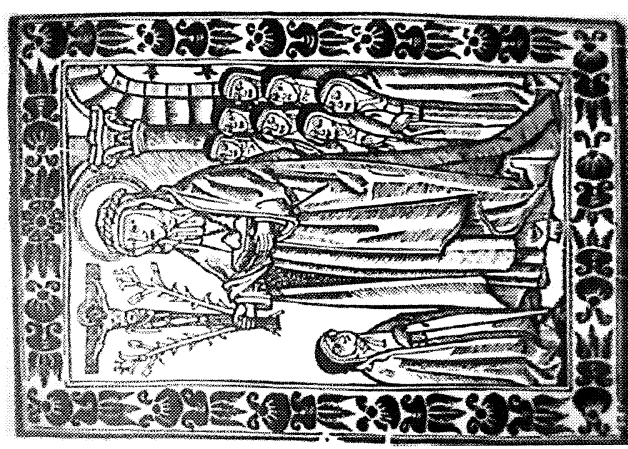

ป

ㅇ

)

ร $\stackrel{5}{\frac{\pi}{2}}$

$\approx$ 放

ฐ $): \frac{0}{0}$

¿

ङ $\quad 0$

는

ปั

कि

$\infty$ in

ㄱ હ

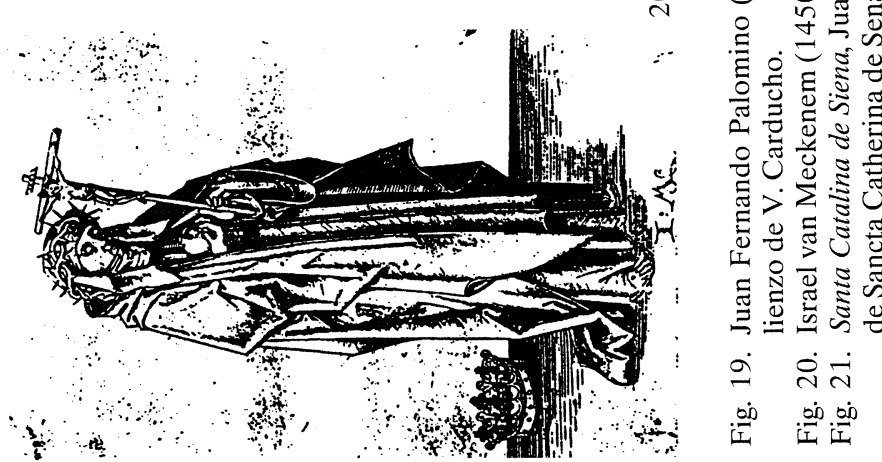

2

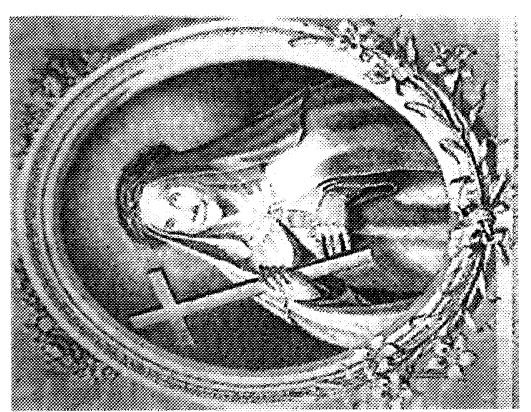

$\stackrel{\infty}{-}$

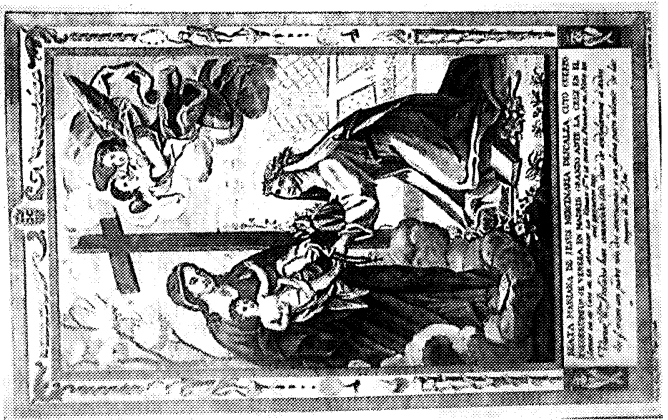

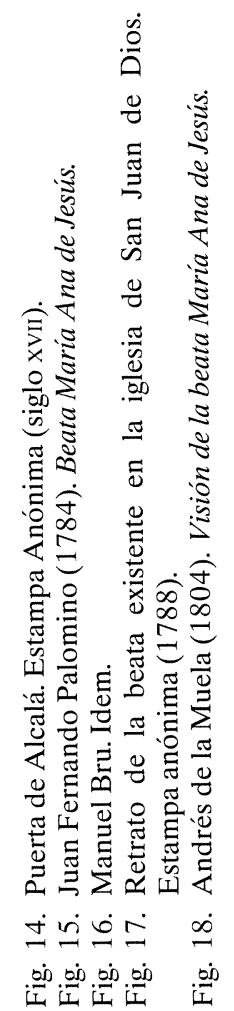


La iconografía de Santa Catalina de Siena, una de las santas con más presencia en la plástica, encontrará en las figuras de los Wierix a sus mejores difusores durante la Epoca Moderna ${ }^{16}$.

$\mathrm{La}$ imagen popularizada por esta genial saga de grabadores flamencos, muy vinculados con las tierras hispanas, presenta a la santa transalpina de medio cuerpo, coronada de espinas y portando un crucifijo y algunas veces el rosario (Figs. 22, 23, 24). Todos estos elementos fueron adoptados para el retrato de Sor María Ana de Jesús, dependencia subrayada por las similitudes de los retratos contemporaneos de ambas santas (Figs. 25, 26) ${ }^{17}$.

De esta forma, cuando se produzca la beatificación de la religiosa mercedaria (1783) y se multipliquen sus retratos, poco restará por inventar, simplemente se recuperará una larga tradición mantenida sin fracturas. Ni siquiera los lienzos de V. Carducho, el primero de los retratistas de la beata madrileña, presentan una iconografía original, sino que adaptan las lineas maestras del retrato de la santa sienense.

Juan Fernando Palomino, copiará uno de los lienzos del italiano poco despues de la beatificación, estableciendo el modelo que seguirán otros artistas, tanto grabadores como escultores (Figs. 27, 28) ${ }^{18}$.

La deuda «iconográfica» de Sor María Ana de Jesús con respecto a Santa Catalina de Siena, se extiende también a la segunda tipología que hemos señalado. Dicha imagen reproduciría la milagrosa aparición de la Virgen con su hijo, ante cuyos pies colocó la beata su rosario. Iconografía que guarda muchas similitudes con una idéntica imagen obra del Sassoferrato, en la iglesia romana de Santa Sabina, protagonizada por Catalina de Siena. El tema sería muy cercano a la composición de los desposorios místicos de Santa Catalina de Siena o su homónima de Alejandría, iconografías con larga tradición en la plástica ${ }^{19}$.

No parece que esta segunda tipología tuviera un amplio desarrollo, podemos señalar al respecto las dos láminas grabadas en los años 1789 y 1804 por Andrés de la Muela y conservada en el Museo Municipal de Madrid.

Los temas «narrativos» como el anteriormente señalado, no tendrán un amplio desarrollo, alcanzando una mayor difusión los retratos con un claro fin devocional ${ }^{20}$. Aunque debemos recordar que una de las primeras imágenes conservadas de la beata madrileña, realizada por Carducho (1625) y hoy en la catedral de Almería, reproducía la "sacra conversación" entre la religiosa mercedaria y Cristo con un fondo paisajístico.

A modo de conclusión, podemos señalar que la iconografía de Sor María Ana de Jesús, como la de otras muchas santas o beatas, tiene su origen en la de Santa Catalina de Siena.

La imagen de la dominica italiana, alcanzaría una notable difusión desde los inicios de la im-

16 Mauquoy-Hendrickx, Marie: Les estampes des Wierix conserves au Cabinet des estampes de la Bibliotheque Royale Albert I, Bruselas (1979), vol. II, p. 147.

17 Se pueden citar, entre otras, las estampas grabadas por Manuel Salvador Carmona, fechada en el año 1792, que presenta grandes similitudes con el retrato de Sor María Ana de Jesús realizada por Juan Fernando Palomino (1790). La imagen ya había sido utilizada por Carmona en el retrato de Santa Rita de Casia por dos veces durante los años 1766 (reproduciendo la escultura de Juan de Mena) y 1767 (a partir del dibujo de Antonio González Velázquez). Vid. Carrete, Juan: El grabado a buril en la España ilustrada: Manuel Salvador Carmona, Madrid (1989), p. 80, n. ${ }^{\circ} 75$, y p. 82 , n..$^{\circ} 82$.

18 Modelo que sigue la lámina grabada por José Gómez de Navía a partir del dibujo de José Rodríguez. La estampa reproducía la escultura de Julián de San Martín existente en la iglesia de Santiago, parroquia donde fue bautizada la beata. Una estampa similar realizada por Manuel Navarro copia la escultura de Sor María Ana de Jesús existente en el convento madrileño de San Juan de Dios, idéntica a la anteriormente señalada. Vid. Arte y devoción. Estampas de imágenes y retablos..., op. cit., p. 37 , n. ${ }^{\circ} 35$, y p. 95, n. ${ }^{\circ} 93$.

19 Reau, Louis: Iconographie de l'art Chrétien, París (1958), vol. III, p. 275.

20 Dentro de este apartado, que podríamos arbitrariamente denominar de narrativo, se podrían incluir láminas como alguna de las conservadas en el Museo Municipal de Madrid, que presentan desde un éxtasis de la religiosa hasta su propio tránsito, esta última impresa en seda. Vid. Catálogo del Gabinete de Estampas del Museo Municipal de Madrid, op. cit., vol. II, núms. 349 y 350 . 


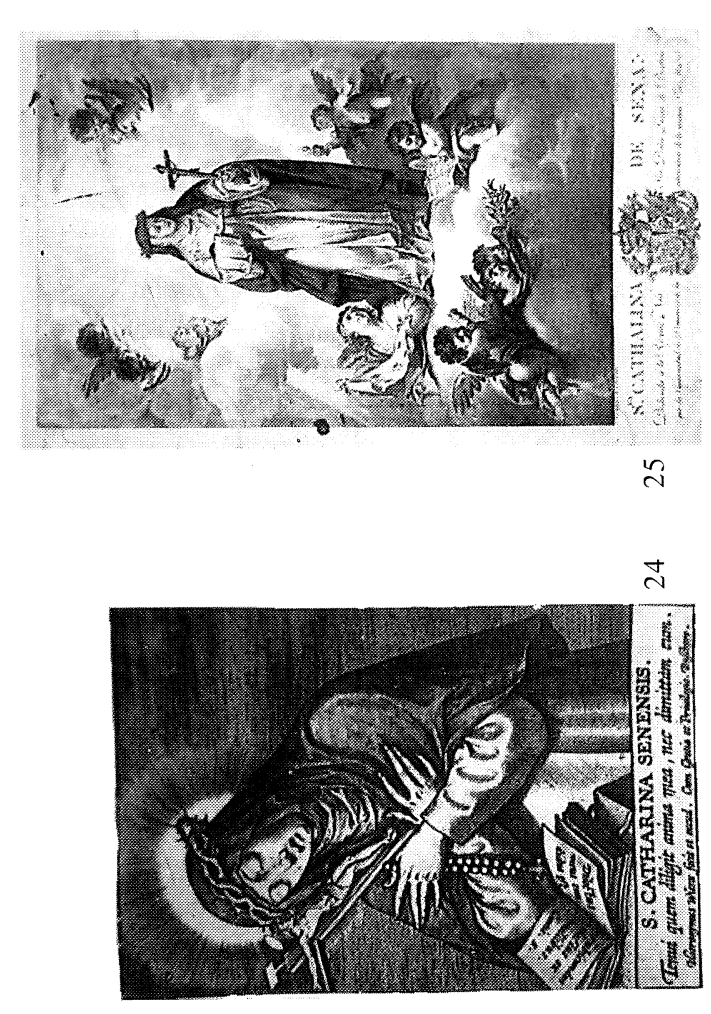

m
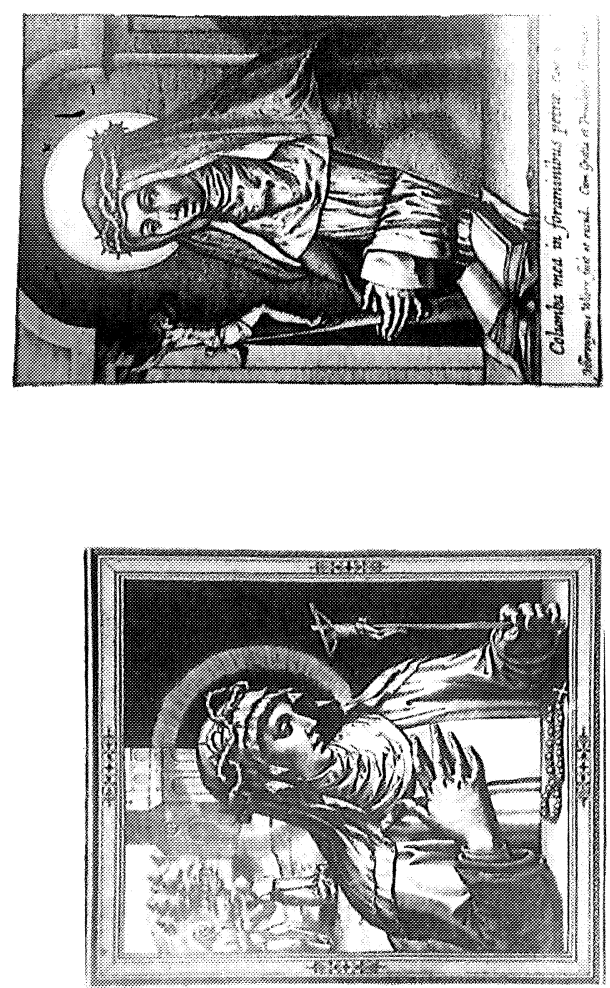

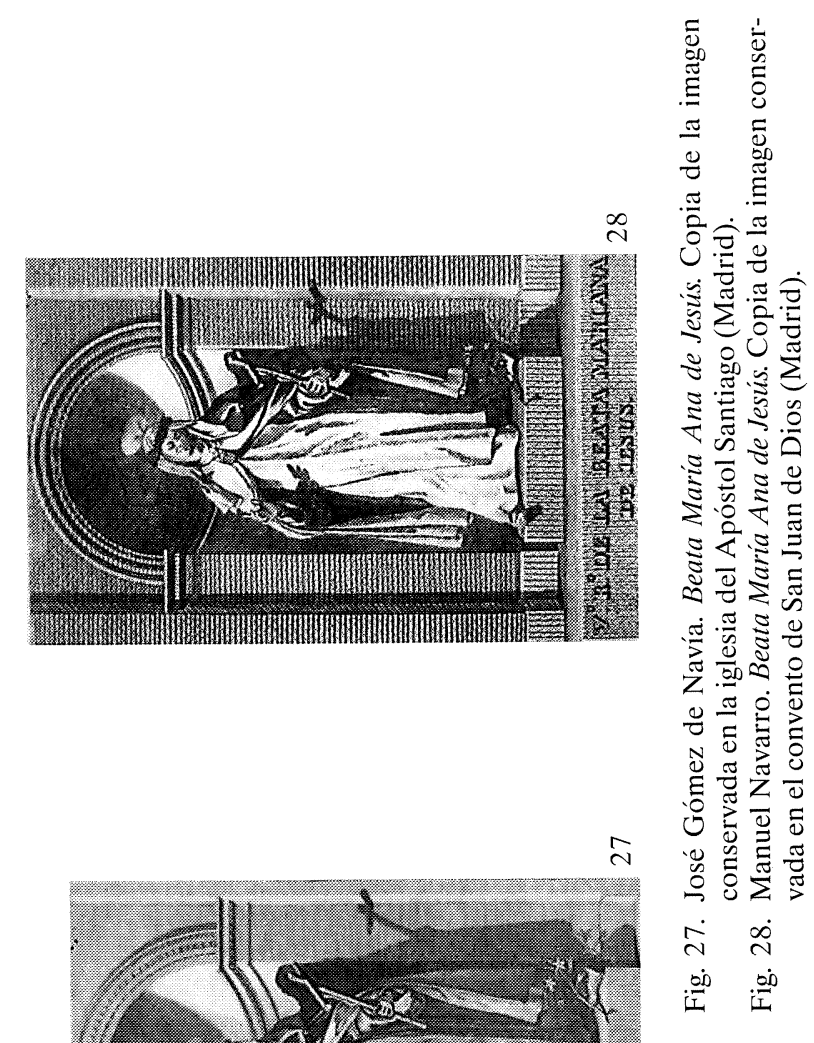

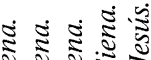

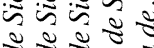

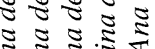

누

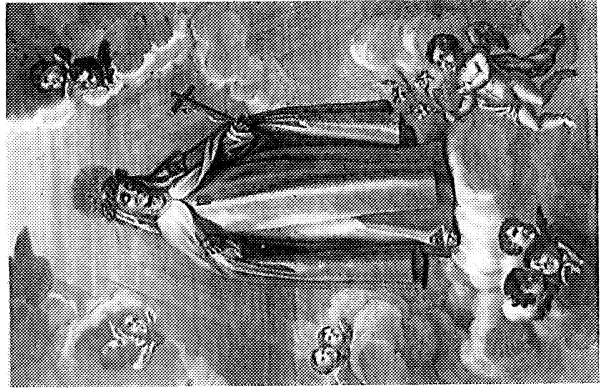

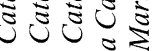

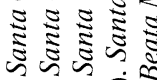

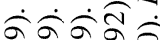

ธำ 옹응

में ले खु

in in in.

$\underset{x . x . x}{=}$

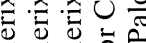

$3>30$

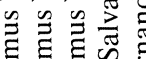

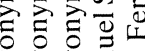

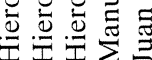

त่

os os on on 
prenta y gracias al grabado. Popularizada en todo el Orbe Católico fundamentalmente por los Wierix desde mediados del siglo xvi, será adaptada a la beata madrileña por su primer retratista, V. Carducho, en la segunda década del siglo XVII.

Es sin duda el italiano quien fija la iconografía física de la mercedaria, ya que como hemos señalado, consiguió la mascarilla funeraria de Sor María Ana de Jesús.

Con la beatificación producida en el ultimo tercio del siglo xVIII, se multiplican los retratos con un claro fin devocional, tomando como modelo los óleos del florentino, alguno de ellos grabado por Juan Fernando Palomino en 1784, poco después de la beatificación. Es probablemente el grabador madrileño el máximo impulsor de la imagen de la beata por cuanto será el artista que más veces la efigie.

Lo ocurrido con la iconografía de Son María Ana de Jesús, mostraría un fenómeno muy extendido en la plástica sacra y resaltaría la histórica relación entre pintura, grabado, escultura y literatura.

VIRGILIO BERMEJo Instituto Ephialte 